\title{
A longitudinal study of smoking in year 7 and 8 students speaking English or a language other than English at home in Sydney, Australia
}

Kwok Cho Tang, Chris Rissel, Adrian Bauman, Joseph Fay, Stuart Porter, Alison Dawes, Barbara Steven

\begin{abstract}
Objective-To compare the rates and predictors of smoking uptake between adolescents speaking English and those speaking a language other than English (LOTE) at home.

Design-A cross-sectional survey of year 7 and 8 students (aged 12 and 13 years) was conducted in 1994 and repeated 12 months later. A cohort of students was identified with respondents at baseline matched at follow up. $\chi^{2}$ and logistic regression were used for analysis.
\end{abstract}

Setting-38 schools in southern, east, and northern Sydney, Australia.

Subjects-Year 7 and 8 students in the schools were included and examined on two occasions, with complete data for 5947 $(80 \%)$ students at baseline and $6177(98 \%)$ students at a 12-month follow up. Records were able to be matched perfectly for 3513 respondents $(59 \%)$.

Main outcome measures-Smoking rates and predictors of smoking uptake among students speaking English or a LOTE at home.

Results-At baseline, $6.1 \%$ of students surveyed were smokers. Twelve months later, $15.8 \%$ of student surveyed were smokers. There were significantly lower smoking rates among students speaking a LOTE at home compared with those speaking English at home at baseline and at 12 months. Using matched data, for students speaking English at home, five variables were significant predictors of smoking uptake: thinking it acceptable to smoke, perceived benefits of smoking, and having a brother, sister, or close friend who smokes. For students speaking a LOTE, the only predictor was the smoking status of close friends.

Conclusions-Despite the higher smoking prevalence among men with a nonEnglish-speaking background, and the reported strong association between fathers' smoking status and smoking onset of their children, adolescents speaking a LOTE at home were significantly less likely to be smokers than their Englishspeaking counterparts. Thus, there would seem to be a delay of smoking onset among students speaking a LOTE at home. The smoking rates among respondents speaking a LOTE at home in this study are lower than those obtained from the studies conducted in Europe and the United States. Effective smoking prevention interventions need to be implemented at an early stage of adolescence.

(Tobacco Control 1998;7:35-40)

Keywords: cigarette smoking, adolescents, ethnicity

\section{Introduction}

Considerable evidence suggests that the smoking status of peers, older siblings, parents, and close adults; perceived benefits of smoking; age; and perceived acceptability of smoking are important predictors of smoking uptake among year 7 and 8 students (aged 12 and 13 years) ${ }^{1-12}$ Ethnicity has sometimes been found to be positively associated with smoking but not consistently. ${ }^{13-17}$

In Australia, although cross-sectional correlates of smoking have been examined, research studies examining predictors of smoking and smoking status among early and late adolescents using a cohort design are not available. Studies targeting adolescents speaking a language other than English (LOTE) at home are also needed because of the high prevalence of smoking among some migrant groups and the positive association between parental smoking status and adolescent smoking. In Sydney at the 1991 census, about $25 \%$ of the total population spoke a language other than English at home. ${ }^{18}$ The smoking prevalence among Australians speaking a LOTE at home was $31.5 \%$ for men aged $20-69$, which was higher than the overall prevalence among Australian men of the same age $(27.0 \%) .{ }^{19}$ The high smoking rates among Australians speaking a LOTE is principally due to the high smoking rates in the larger ethnic groups. Of the 66 language groups tabulated by the Australian Bureau of Statistics, those who speak Chinese (14.2\%), Arabic including Lebanese (14.2\%), Italian (11.5\%), Greek $(11.2 \%)$, and Vietnamese $(5.1 \%)$ accounted for about $57 \%$ of those speaking a LOTE at home. As revealed through ethnic-specific prevalence studies within defined geographical areas, the smoking rates among men in these major ethnic groups are higher than the total Australian prevalence in men, with $53 \%$ for Vietnamese, 44\% for Greek, 43\% for Arabic, $33 \%$ for Italians, and $26 \%$ for Chinese. ${ }^{20-24}$

Despite the higher smoking prevalence among adults with a non-English speaking background and the previously reported strong 
Table 1 Participating and non-participating schools by type of school

\begin{tabular}{|c|c|c|c|c|c|c|}
\hline & \multicolumn{2}{|c|}{ Government } & \multicolumn{2}{|c|}{ Non-government } & \multicolumn{2}{|c|}{ Total } \\
\hline & $\begin{array}{l}\text { Participant } \\
n\end{array}$ & $\begin{array}{l}\text { Non-participant } \\
n\end{array}$ & $\begin{array}{l}\text { Participant } \\
n\end{array}$ & $\begin{array}{l}\text { Non-participant } \\
n\end{array}$ & $n$ & $\%$ \\
\hline \multicolumn{7}{|l|}{ South Eastern } \\
\hline Sydney & 22 & 11 & 9 & 26 & 68 & 79 \\
\hline \multicolumn{7}{|l|}{ North } \\
\hline Sydney* ${ }^{\star}$ & 7 & 11 & NA & NA & 18 & 21 \\
\hline Total & 29 & 22 & 9 & 26 & 86 & 100 \\
\hline
\end{tabular}

${ }^{\star}$ One school dropped out from the follow-up survey.

tOnly Government schools located within the beachside suburbs were invited because of the need to approximate the socioeconomic student profile of the schools included in the

intervention group.

$\mathrm{NA}=$ not applicable and non-government schools in this sample was the same as that of the statewide survey. ${ }^{29}$ Of the 38 participating schools, one school dropped out from the follow-up study. A profile of the participating and nonparticipating schools is given in table 1 .

RESPONSE RATE OF STUDENTS

Of students enrolled in years 7 and 8 in the study schools $(n=8598)$, baseline data were collected from 7394 (86\%). Absentees accounted for about $6 \%$ of eligible students. Non-participants accounted for the remaining $8 \%$ of students. The response rate was again similar to that of the 1992 New South Wales statewide survey in which respondents comprised $89 \%$ of those eligible to participate. Complete data were available from 5947 respondents $(80 \%)$. At 12 months, there were 6296 responses from a total of 7321 students, of which 6177 (98\% of respondents) had complete data. Records were able to be matched perfectly for 3513 respondents $(59 \%$ of the baseline sample) using respondent-generated identity codes. No attempt was made to classify absentee students at baseline or follow up. many non-English-speaking European countries were much higher than in the English-speaking countries. Research in the United States also revealed that there were high smoking rates among adolescents in some minority populations. ${ }^{27} 28$

Using longitudinal data from a sample of adolescents in Sydney, this study aims to compare the rates and predictors of smoking between adolescents speaking English and a language other than English at home, and to highlight the implications of these findings for the development of effective preventive interventions.

\section{Methods}

Data for this study were collected as baseline and at follow up 12 months later for the "Kickbutts" smoking prevention programme. The programme aims to reduce smoking uptake among year 7 and 8 high-school students through a combination of school-based strategies, parental support, and supply-reduction strategies. Respondents at baseline were students in years 7 and 8 (approximately 12 and 13 years old) in 38 schools in the South Eastern and Northern Sydney Area Health Services, two area health services with generally similar socioeconomic profiles.

SELECTION OF SCHOOLS

Eighty-six schools were invited to participate and 38 schools (44.2\%) agreed to take part in the baseline study. To participate in the study, schools were asked to assign a teacher to deliver a designated school-based smoking prevention package for their year 7 and 8 students. The main reason for nonparticipation was the practical difficulties the schools faced in implementing the intervention. There appear to be no other factors that might have biased the selection. Although the school participation rate was much lower than that of the 1992 statewide survey in New South Wales (NSW), the ratio between government

\section{INSTRUMENT}

Identical baseline and follow-up questionnaires consisted of 42 items concerning self-reported cigarette smoking behaviour, peer and family smoking behaviour, perceptions of the benefits of smoking (a four-point scale), language spoken at home, and demographic data. Most questions used were single items drawn from the NSW Drug and Alcohol Directorate's 1989 survey of drug use by NSW secondary students. ${ }^{30}$

Smoking status of students was assessed by asking students to indicate whether they were regular smokers (at least one cigarette a day), occasional smokers (smoked once or twice only, smoked occasionally in the past, occasionally now but not regularly), exsmokers (smoked regularly in the past), or never-smokers. Students were also asked to indicate the smoking status of their family members, close friends and other adults who were close to them.

The assessment of perceived benefits of smoking consisted of four questions. Respondents were asked to indicate on a four-point scale (strongly agree, agree, disagree, or strongly disagree) their agreement with the following statements: smoking helps people keep thin, smokers are usually more popular than non-smokers, people who smoke are usually more mature than non-smokers, and smokers usually look better than non-smokers.

Language spoken at home was assessed by the question "What language do you speak at home?". Respondents who spoke a LOTE were then asked to specify the language. Responses were coded as English or a LOTE.

Additional questions developed by the research team asked whether respondents thought it acceptable for people their own age to be smoking cigarettes and whether parents had discussed smoking with them. Parental discussions with children consisted of two 
Table 2 Percentage of students smoking in years 7 and 8, 12 months later, and a sub-sample of these students with matched data

\begin{tabular}{llcrrrl}
\hline & $n$ & Overall $\%$ & ES $\%$ & LOTE $\%$ & $\chi^{2}$ & $p$ \\
\hline 1994 survey & 5947 & 6.1 & 7.1 & 3.0 & 32.4 & $<0.001$ \\
1995 survey & 6177 & 15.8 & 17.2 & 11.0 & 29.6 & $<0.001$ \\
1994 subsample (matched data) & 3513 & 4.6 & 5.6 & 0.8 & 30.3 & $<0.001$ \\
1995 subsample (matched data) & 3513 & 12.1 & 13.4 & 7.3 & 23.8 & $<0.001$ \\
\hline
\end{tabular}

ES = English speaking; LOTE = language other than English.

questions. Students were asked whether their mother or father talked to them about how to say "no" to other people offering them cigarettes and whether their mother or father discussed smoking with them within 12 months before the interview. The questionnaire was piloted among approximately 100 year 7 and 8 students from schools that declined to participate in the programme.

QUESTIONNAIRE ADMINISTRATION

Baseline data were collected consecutively as schools were recruited. Students were invited to fill in a baseline questionnaire in either term 1 or 2 in 1994, and another identical questionnaire again in term 2 in the 1995 follow-up study. Administration of the questionnaire was carried out by project officers and a strict protocol was followed. The need for silence and no discussion of questions with peers was emphasised. Where the school felt it necessary for discipline, a teacher was also on hand. The teacher was asked to remain in the front or at the back of the school hall or classroom. The project officer described the purpose of the survey to the students, gave standardised instructions for completing the questionnaire, and emphasised the confidentiality and anonymity of responses. These procedures were based on the Department of Community Services guidelines for comparability of drug use surveys. ${ }^{31}$

\section{CODING AND COHORT IDENTIFICATION}

Questionnaires were coded by university students and clerical assistants under the supervision of a project officer in accordance with the coding specifications. Coding was then audited by three project officers before being entered by a data processing firm, which entered and rechecked all entries with an accuracy rate of $99.95 \%$. Data were coded and entered in different data sets.

Although data were collected in two independent cross-sectional surveys, a cohort was determined by matching baseline and follow-up records using unique and anonymous respondent-generated identification codes: name code; year of study; and gender. The name code consisted of four letters, beginning with the first letter of the student's given name, followed by the first three letters of his or her family name. To this alpha-numeric string was added a three-digit school identification code. Records with perfect matches and no duplications were included in the longitudinal analysis.

DATA ANALYSIS

The dependent variable, smoking status, was dichotomised into "current smoker" and "non-smoker", with "current smoker" including regular smokers of one or more cigarettes a day and those who smoked "occasionally now but not regularly". The primary independent variable was whether English or a language other than English was spoken at home. Additional independent variables were selected according to social learning theory, which posits that an individual's susceptibility to perform a particular behaviour is influenced by three types of factors that interact with each other in complex ways-personal, environmental, and behavioural influences. ${ }^{10}$ The four items concerning perceived benefits of smoking were totalled to yield an aggregate score. Cronbach's $\alpha$ for the four items in the scale at baseline was 0.69 . Frequencies and cross-tabulations of variables were computed to estimate the rates of smoking for the total samples at baseline and at 12 months, and at 12 months for the cohort with complete data at both time points. Using data for baseline non-smokers, simultaneous logistic regression was used to calculate the odds of becoming a smoker. Predictors of smoking were baseline values of language use and social-environmental variables. Records with missing data for the dependent and independent variables were excluded from the logistic regression analysis.

\section{Results}

At baseline, $6.1 \%$ of the sample were smoking. Twelve months later $15.8 \%$ of the sample were smoking. The proportion of students smoking at follow up in the matched cohort was $12.1 \%$. Students speaking English at home were consistently more likely to be smokers than students speaking a language other than English at home (table 2). Three quarters of the students $(73.5 \%)$ spoke English at home. The most frequently spoken LOTE at home was Arabic (7.7\%), followed by Chinese (3.9\%), Greek (2.7\%), and Macedonian $(1.5 \%)$. The remaining students spoke at least one of 47 other languages. The population of students speaking a LOTE was similar in the cohort and cross-sectional samples. The proportion of males was slightly lower (51\%) in the cohort than in the cross-sectional sample $(55 \%)$. There were only 23 smoking students who spoke Arabic, Chinese, Greek, Italian, or Vietnamese in the cross-sectional study.

Among the students in the cohort, the prevalence of smoking among girls and boys was similar, with girls slightly more likely to be smokers than boys at baseline and follow up, whether speaking English or another language at home. At baseline, $5.8 \%$ of English-speaking girls were smokers compared with $5.3 \%$ of boys, and at follow up $13.8 \%$ of English-speaking girls were smokers compared with $12.9 \%$ of boys. At baseline, $1.0 \%$ of girls speaking a language other than English were smokers compared with $0.6 \%$ of boys. At follow up $7.9 \%$ of girls speaking a language other than English were smokers compared with $6.5 \%$ of boys.

Fathers speaking a language other than English at home were significantly more likely to be smokers (37.7\%) than fathers speaking English 
Table 3 Language use and social environmental predictors of smoking status among baseline non-smokers between years $7-8$ and years $8-9$ among Sydney students $(n=3353)$

\begin{tabular}{lrrr}
\hline Variables & $\%$ & $\begin{array}{l}\text { Odds } \\
\text { ratio }\end{array}$ & $95 \%$ CI \\
\hline Year 7 & 52.7 & 1.00 & \\
Year 8 & 47.3 & 1.17 & $0.92-1.51$ \\
Female & 48.7 & 1.00 & \\
Male & 51.3 & 1.04 & $0.81-1.32$ \\
Think not acceptable to smoke & 10.6 & 1.00 & \\
Think acceptable to smoke & 89.4 & 1.81 & $1.32-2.49$ \\
Perceived benefits of smoking & $\star$ & 1.12 & $1.06-1.19$ \\
Parents not discussed smoking & 36.4 & 1.00 & \\
Parents discuss smoking with student & 63.6 & 1.18 & $0.92-1.53$ \\
Father does not smoke & 74.2 & 1.00 & \\
Father smokes & 25.8 & 0.94 & $0.70-1.26$ \\
Mother does not smoke & 81.4 & 1.00 & \\
Mother smokes & 18.6 & 0.93 & $0.67-1.28$ \\
Brother does not smoke & 92.6 & 1.00 & \\
Brother(s) smokes & 7.4 & 1.73 & $1.19-2.52$ \\
Sister does not smoke & 93.8 & 1.00 & \\
Sister(s) smokes & 6.2 & 1.73 & $1.10-2.57$ \\
Close friends do not smoke & 70.4 & 1.00 & \\
Close friend(s) smokes & 29.6 & 2.32 & $1.80-3.00$ \\
Other close adults do not smoke & 44.2 & 1.00 & \\
Other close adult(s) smokes & 55.8 & 1.18 & $0.92-1.52$ \\
Speaks language other than English at home & 21.9 & 1.00 & \\
Speaks English at home & 78.1 & 1.42 & $1.01-1.99$ \\
( & & &
\end{tabular}

${ }^{\star}$ Continuous variable.

$\mathrm{CI}=$ confidence interval

Table 4 Social environmental predictors of smoking status by language use among a cohort of years 7 and 8 Sydney students (3352)

\begin{tabular}{|c|c|c|c|c|}
\hline \multirow[b]{2}{*}{ Variables } & \multicolumn{2}{|c|}{$\operatorname{LOTE}(n=734)$} & \multicolumn{2}{|c|}{$E S(n=2618)$} \\
\hline & $O R$ & $95 \% C I$ & $O R$ & $95 \% C I$ \\
\hline Year 7 & & 1.00 & & \\
\hline Year 8 & 1.42 & $0.75-2.71$ & 1.13 & $0.86-1.48$ \\
\hline Female & & 1.00 & & \\
\hline Male & 1.19 & $0.64-2.21$ & 1.01 & $0.78-1.32$ \\
\hline Think not acceptable to smoke & & 1.00 & & \\
\hline Think acceptable to smoke & 1.14 & $0.38-3.45$ & 1.92 & $1.38-2.69$ \\
\hline Perceived benefits of smoking & 1.13 & $0.98-1.31$ & 1.12 & $1.05-1.20$ \\
\hline Parents not discussed smoking & & 1.00 & & \\
\hline Parents discuss smoking with student & 1.24 & $0.64-2.45$ & 1.17 & $0.89-1.55$ \\
\hline Father does not smoke & & 1.00 & & \\
\hline Father smokes & 1.45 & $0.76-2.77$ & 0.82 & $0.59-1.15$ \\
\hline Mother does not smoke & & 1.00 & & \\
\hline Mother smokes & 1.17 & $0.54-2.54$ & 0.89 & $0.62-1.26$ \\
\hline Brother does not smoke & & 1.00 & & \\
\hline Brother(s) smokes & 1.93 & $0.20-5.05$ & 1.77 & $1.18-2.67$ \\
\hline Sister does not smoke & & 1.00 & & \\
\hline Sister(s) smokes & 1.36 & $0.40-4.65$ & 1.78 & $1.17-2.70$ \\
\hline Close friends do not smoke & & 1.00 & & \\
\hline Close friend(s) smokes & 2.17 & $1.09-4.29$ & 2.35 & $1.78-3.12$ \\
\hline Other close adults do not smoke & & 1.00 & & \\
\hline Other close adult(s) smokes & 0.76 & $0.47-1.67$ & 1.26 & $0.95-1.66$ \\
\hline
\end{tabular}

ES = English speaking $;$ LOTE = language other than English; $\mathrm{OR}=$ odds ratio; $\mathrm{CI}=$ confidence interval. compared with $5.9 \%$ if the father was a non-smoker $\left(\chi^{2}=3.5, \mathrm{p}=0.061\right)$.

There was a significant increase in the prevalence of smoking in children if one parent smoked $(13.3 \%)$ or both parents smoked $(17.2 \%)$ compared with neither parent smoking (10.8\%) (Mantel-Haenszel $\chi^{2}=14.3$, $\mathrm{p}=0.001)$. This trend was consistent for children speaking a language other than English at home (Mantel-Haenszel $\chi^{2}=12.1, \mathrm{p}=0.001$ ) or English (Mantel-Haenszel $\chi^{2}=6.5, \mathrm{p}=$ 0.011 ) but did not remain an independent predictor of smoking after adjustment for other variables in multivariate analyses.

Using only the data which was able to be matched perfectly at baseline and follow up ( $\mathrm{n}=3513), 160(4.6 \%)$ students smoked and $3353(95.5 \%)$ were non-smokers at baseline. Of baseline non-smokers, 308 (9.2\%) were smokers one year later. When these new smokers were compared with never-smokers (3045), six variables proved to be significant independent predictors of smoking status (table 3). These variables were thinking it acceptable to smoke; perceiving there to be benefits of smoking; having a brother, sister, or close friend who smokes; and speaking English at home. The strongest predictor of smoking was having a close friend(s) who smokes.

Language spoken at home was independently and significantly associated with smoking using cross-sectional data at baseline $(\mathrm{OR}=$ $1.47 ; 95 \%$ confidence interval $(\mathrm{CI})=1.02$ to $2.11)$ and at follow up $(\mathrm{OR}=1.27 ; 95 \% \mathrm{CI}=$ 1.00 to 1.61 ), although the strength of this association was weaker at follow up.

As revealed in table 4, logistic regression analysis identified five significant variables associated with smoking status after adjusting for all variables in the model for students speaking English at home, but only one was identified for students speaking a language other than English at home.

\section{Discussion}

The proportion of students smoking at baseline had doubled at follow up. Language spoken at home emerged as an independent predictor of smoking status 12 months later after adjusting for other social environment variables. The lower smoking prevalence among respondents speaking a LOTE at home was unexpected given the higher male smoking prevalence among the major non-Englishspeaking migrant population, the strong positive association between fathers' smoking status and smoking onset of their children, and high rates of adolescent smoking demonstrated previously in many European countries ${ }^{26}$ and some minority populations in the United States. ${ }^{27}{ }^{28}$ However, findings of this study support the argument of Conrad and colleagues ${ }^{7}$ that parental smoking behaviour plays a much less consistently important role in predicting onset among adolescents, and that one parent may have influence and not the other, as revealed in the bivariate analyses between parental smoking status and student smoking prevalence. pared with $6.2 \%$ if the mother was a non-smoker $\left(\chi^{2}=5.3, p=0.021\right)$, and $9.5 \%$ of students were smokers if the father smoked 
The lower smoking rate in students speaking a language other than English at home may be due to three reasons. First, these adolescents may be responding to strong parental control in which parents take a strict stance against smoking regardless of their own actual smoking behaviour. In a separate but related analysis yet to be published, we found that mothers of students speaking English at home were less likely to have enforced strict rules about not smoking $\left(\chi^{2}=11.2, p=0.001\right)$ than mothers of those respondents speaking a language other than English at home. (Maternal action data from the same project were analysed separately to examine this question.) Literature is available that shows that strictness of parents leads to a lower prevalence of cigarette uptake among adolescents, regardless of parents' own smoking behaviour. ${ }^{913}$ The low smoking rates among students speaking a LOTE despite parental smoking, may be consistent with data from black American families, where adults, even those who smoke, have significant more negative views on cigarette smoking than white Americans. ${ }^{32}$

Second, students speaking a language other than English at home may also socialise with peers of their own language group, all of whom may have a strong family restriction on adolescent smoking. More importantly, findings of this study reveal that close friends' smoking status was the only predictor of smoking onset among students speaking a language other than English. It is possible that students speaking a language other than English at home smoke less because they have fewer close friends who are smokers, compared with their counterparts speaking English at home.

A third explanation for the lower smoking rates among students speaking a LOTE may be that they have not yet been targeted specifically by the advertising campaigns of the tobacco industry as has been the case for young women over the past 10 years in Australia.

Despite the relatively lower smoking rate among students speaking a language other than English at home, compared with the students speaking English at home, there was a relatively greater increase in uptake among students speaking a language other than English at home using either the matched or unmatched data. The lower prevalence among students speaking a LOTE at home may reflect a temporary response to strong parental control in which parents take a rigid stance against smoking regardless of their actual smoking behaviour: "Do as I say, not as I do." Once these students become older, parental supervision is less effective. As reported by Quine and Stephenson, ${ }^{32}$ parental influence will likely be especially strong in preadolescents. Klesges and Robinson ${ }^{33}$ also reported that the negative views on cigarette smoking held by African American parents may be temporarily effective in delaying the uptake of cigarette smoking in their children, but not in preventing it. This phenomenon might explain the Israeli experience, in which smoking rates among Israeli teenagers increase most markedly at 18 years of age when they are required to join the army where smoking is common among their peers (personal communication with Professor Don Nutbeam, 1988).

As the data collection was in English, it was not known whether the rates of smoking were under-reported for two reasons. It is not known if English proficiency of students having a nonEnglish-speaking background influenced their responses. In addition, the validity and reliability of self-reported smoking behaviour in these students is not known.

The moderate matching of students in the cohort meant some differences between the cohort and the cross-sectional samples. Fewer males in the cohort group may have reduced their smoking rate but the overall proportion of students speaking a LOTE was similar in the cohort and cross-sectional samples.

Findings of the baseline, follow up, and cohort study also revealed that a strong positive association exists between adolescent tobacco use and thinking that it is acceptable to smoke. The baseline 1994 survey and follow-up 1995 survey show that thinking smoking was acceptable was associated with a 5-7-fold increase in actual smoking, although the cross-sectional design does not allow a conclusion as whether the relationship was causal. We had suspected that this belief could be a rationalisation among respondents of this study of their smoking behaviour. However, findings from table 3 reveal that this belief was not merely a rationalisation of their smoking but a significant causal factor contributing to smoking uptake among adolescents.

Consistent with theoretical expectations, ${ }^{4-8}$ findings of this study, as shown in table 3, also revealed that the smoking status of peer and siblings, and perceived benefits of smoking, were antecedent predictors of smoking onset among adolescents.

It is important to note that, as shown in table 4 , only one predictor of smoking uptake was identified among students speaking a language other than English at home. Reasons for this may include smaller numbers and hence reduced statistical power, and the necessity to aggregate data for all non-English-speaking groups. There may be other aetiological variables for smoking uptake among these students that need to be identified in future Australian studies. Parents' rules and attitudes towards adolescent smoking have been found to significantly influence the uptake of smoking in migrant groups. ${ }^{131428} 34$

A limitation of this study relates to the small numbers of students from specific ethnic backgrounds and the need to aggregate data by whether students speak English or some other language at home. As the number of smoking students speaking either Chinese, Arabic, Italian, Greek, and Vietnamese was very small, the assessment of rates and factors of cigarette smoking among specific ethnic communities was not feasible. However, this aggregation did not mask the low adolescent smoking rates of student speaking a LOTE. As a result of this study, the smoking rates among students speaking a LOTE in the 1986, 1989, and 1992 New South Wales Statewide Surveys were 
examined and the low smoking rates among students speaking a LOTE in this study have been confirmed (Chen et al, unpublished observations).

IMPLICATIONS FOR PRACTICE

The understanding of changes in predictors of smoking uptake and smoking status of the respondents of this study is useful for the development of effective interventions in the reduction of smoking rates among adolescents. The messages that smoking is not acceptable and that there are no benefits of smoking must be passed onto adolescents clearly, strongly, and appropriately. Role modelling by close friends and possibly siblings would seem to be more important than that by parents. Regardless of their smoking status, parents need to adopt strict rules about not smoking. Parental disapproval of smoking in the forms of feeling upset, threatening to punish, and warning never to smoke may lead to a lower prevalence of cigarette uptake among adolescents. ${ }^{9}$ However, strict parental supervision may be a double-edged sword and may lead to a sharp increase in smoking onset among adolescents at a later stage. Therefore, parents may need to adopt an alternative approach which involves discussion and sharing opinions when their children become older.

To prevent smoking uptake among adolescents, it would seem important to develop early and effective interventions. A comprehensive approach which aims to develop personal skills and knowledge of adolescents on the one hand and to provide a supportive environment on the other is recommended. ${ }^{26}$ While prevention may be the best strategy (in terms of value for money) to reduce the onset of cigarette smoking, it is also important to consider effective cessation programmes for adolescents. ${ }^{35}$ Prevention programmes may not help adolescents who have already begun to smoke.

This project was carried out at the Health Promotion Unit, South Eastern Sydney Area Health Service. The authors wish to thank the students and teachers of the 38 schools for their participation in this study and the NSW Drug and Alcohol Directorate, NSW Health Promotion Unit, the St George Hospital torate, NSW Health Promotion Unit, the St George Hospital
and Community Health Service, and the Sutherland Hospital and Community Health Service for funding this study.

1 Aaro L, Bruland E, Hauknes A, et al. Smoking among Norwegian school children 1975-1980: the effects of antismoking campaigns. Scand f Psychol 1982;24:277-83.

2 Alexander H, Callcott R, Dobson A, et al. Cigarette Alexander H, Callcott R, Dobson A, et al. Cigarette
smoking and drug use in schoolchildren: IV. Factors associated with changes in smoking behaviour. Int f Epidemiol ciated with changes

3 Armstrong B, de Klerk N, Shean R, et al. Influence of education and advertising on the uptake of smoking by children. Med $\mathcal{F}$ Aust 1990;152:117-24.

4 Bauman K, Fisher L, Bryan E, et al. Antecedents, subjective expected utility, and behavior: a panel study of adolescent cigarette smoking. Addict Behav 1984;9:121-36.

5 Bauman K, Foshee V, Linzer M, et al. Effect of parental smoking classification on the association between parental and adolescent smoking. Addict Behav 1990;15:414-22.

6 Chassin L, Presson C, Sherman S, et al. Predicting the onset of cigarette smoking in adolescents: a longitudinal study. $\mathcal{F}$ Appl Soc Psychol 1984;14:224-43.

7 Conrad K, Flay B, Hill D. Why children start smoking cigarettes: predictors of onset. Br f Addict 1992;87:1711-24.

8 McCaul K, Glasgow R, O'Neill, H, et al. Predicting adolescent smoking. F Sch Health 1982;52:342-6.
9 Newman I, Ward J. The influence of parental attitude and Newman I, Ward J. The influence of parental attitude and
behavior on early adolescent cigarette smoking. I Sch Health 1989;59:150-2.

10 Pierce J, Farkas A, Evans N, et al. Tobacco use in California 1992: a focus on preventing uptake in adolescents. Sacramento, California: California Department of Health Services, 1993.

11 Shean R, de Klerk N, Armstrong B, et al. Seven-year follow up of a smoking prevention program for children. Aust $\mathcal{F}$ Public Health 1994;18:205-8.

12 Working Party on Smoking and the Young. Smoking and the young. London: Royal College of Physicians of London, young.

13 de Moor C, Elder J, Young R, et al. Generic tobacco use among four ethnic groups in a school age population. $\mathcal{f}$ Drug Educ 1989;19:257-70.

14 McDermott R, Sarvela P, Hoalt P, et al. Multiple correlates of cigarette use among high school students. F Sch Health 1992;62:146-50.

15 Geronimus L, Neidert L, Bound J. Age patterns of smoking in US Black and White women of child bearing age. Am $\mathcal{f}$ Public Health 1993;83:1258-64.

16 Marcus A, Crane L. Smoking behaviour among US Latinos: an emerging challenge for public health. Am f Public Health 1985;75:169-72.

17 Orleans C, Schoenbach V, Salmon M, et al. A survey of smoking and quitting patterns among Black Americans. Am f Public Health 1989; 79:176-81.

18 Australian Bureau of Statistics. Census characteristics of New South Wales (ABS Catalogue No 2710.1). Canberra, ACT: Australian Government Publishing Service, 1991.

19 Bennett S. Risk factor differentials among immigration groups. In Donovan J, D'Espainget E, Merton C, et al, eds. Immigrants in Australia: a health profile. Australian Institute of Health and Welfare Ethnic Health Series No 1. Canberra, ACT: Australian Government Publishing Serv-

20 Rissel C, Russell C. Heart disease risk factors in the Vietnamese community of south-western Sydney. Aust $\mathcal{F}$ Public Health 1993;17:71-3.

21 Gleeson S. Heart disease risk factor prevalence studyItalian-Australians in Central Sydney Area Health Service. Master of Public Health treatise, University of Sydney, 1995.

22 Farrell D, Wraight R. State of health in New South Wales. Australian Bureau of Statistics and NSW Department of Health (ABS Catalogue No 4330.1). Canberra, ACT: Australian Government Publishing Service, 1993.

23 Wilson A, Bekiaris J, Gleeson S, et al. The Good Heart, Good Life Survey: Self-reported cardiovascular disease risk factors, health knowledge and attitudes among GreekAustralians in Sydney. Aust f Public Health 1993;17:21521.

24 Hage B, Wahlqvist M. Cardiovascular risk in adult

Tang K C, Rissel C, Fay J et al. Rates and correlates of cigarette smoking among a sample of year 7 and 8 students-a comparative study between students speaking English and a language other than English at home. Internet $\mathcal{F}$ Health Prom 1997. www.monash.edu.au/health/IJHP/1997/5.

26 Nutbeam D, Mendoza R, Newman, R. Planning for a smokefree generation-Smoke-free Europe 6. Copenhagen: WHO Regional Office for Europe and the Commission of the European Communities, 1988

27 Dusenbury L, Kerner J, Baker E, et al. Predictors of smoking prevalence among New York Latino youth. Am f Public Health 1992;82:55-8.

28 Dusenbury L, Epstein J, Botvin G, et al. The relationship between language spoken and smoking among HispanicLatino in New York City. Public Health Rep 1994;109:4217 .

29 Cooney A, Dobbinson S, Flaherty B. Drug use by NSW secondary students - 1992 survey. Sydney, NSW: Department of Health, 1993.

30 Donnelly N, Quine S, Oldenburg B, et al. Prevalences and perceptions of licit and illicit drugs among New South Wales secondary students, 1989. Aust $\mathcal{F}$ Public Health 1992;16:43-9.

31 Commonwealth Department of Community Services and Health. Methodology for comparability between jurisdictions for drug use survey. Canberra, ACT: Australian Government Publishing Service, 1990.

32 Quine S, Stephenson J. Predicting smoking and drinking intentions and behaviour of pre-adolescents: the influence of parents, siblings and peers. Fam Syst Med 1990;8:191200.

33 Klesges R, Robinson L. Predictors of smoking onset in adolescent African American boys and girls. F Health Educ 1995;26:85-91.

34 Headen S, Bauman K, Deane G, et al. Are the correlates of cigarette smoking initiation different for black and white adolescents? Am f Public Health 1991;81:854-7.

35 Vartiainen E, Fallonen U, McAlister A, et al. Eight-year follow up results of an adolescent smoking prevention program: the North Karelia Youth Project. Am f Public Health 1990;80:78-9. 